\title{
Modelo de educação no período de pandemia: discussão a respeito das suas implicações no desenvolvimento da criança e do adolescente
}

Education model in the pandemic period: discussion about its implications for the development of children and adolescents

\author{
Carla Liliane Waldow Esquivel ${ }^{1}(\mathbb{D})$, Danielly Tavares Bueno Sferra ${ }^{2}$ (D), Bettina Lays dos $\operatorname{Santos}^{3}$ (iD), Natália \\ Batista Pontes $^{4}$ (D) e Viviane Barbosa Dorecki ${ }^{5}$ (D)
}

\begin{abstract}
${ }^{1}$ Docente do curso de Direito da Universidade Estadual do Oeste do Paraná (UNIOESTE), coordenadora e orientadora Pedagógica do Núcleo de Estudos e Defesa dos Direitos da Infância e da Juventude (NEDDIJ), doutora em Direito do Estado pela Universidade Federal do Paraná. Mestre em Direito Penal pela Universidade Estadual de Maringá, líder do Grupo de Pesquisas e Estudos em Primeira Infância (GEPEPI), e-mail: carlawaldow@ hotmail.com

${ }^{2}$ Advogada Bolsista do Núcleo de Estudos e Defesa dos Direitos da Infância e da Juventude (NEDDIJ) da Universidade Estadual do Oeste do Paraná (UNIOESTE), Campus de Marechal Cândido Rondon, especialista em Políticas de Atenção à Criança e Adolescente pela Universidade Estadual do Oeste do Paraná (campus Francisco Beltrão) e em Direito Constitucional pelo Complexo de Ensino Renato Saraiva, membro do Grupo de Pesquisas e Estudos em Primeira Infância (GEPEPI), e-mail: daniellysferra@gmail.com

${ }^{3}$ Pedagoga Bolsista do Núcleo de Estudos e Defesa dos Direitos da Infância e da Juventude (NEDDIJ) da Universidade Estadual do Oeste do Paraná (UNIOESTE), Campus de Marechal Cândido Rondon, membro do Grupo de Pesquisas e Estudos em Primeira Infância (GEPEPI), e-mail: betty-lays@ @otmail.com

${ }^{4}$ Estagiária do Curso de Direito no Núcleo de Estudos e Defesa dos Direitos da Infância e da Juventude (NEDDIJ) da Universidade Estadual do Oeste do Paraná (UNIOESTE), Campus de Marechal Cândido Rondon, membro do Grupo de Pesquisas e Estudos em Primeira Infância (GEPEPI), e-mail: nah_bpontes@hotmail.com

${ }^{5}$ Estagiária do Curso de Pedagogia no Núcleo de Estudos e Defesa dos Direitos da Infância e da Juventude (NEDDIJ) da Universidade Estadual do Oeste do Paraná (UNIOESTE), Campus de Marechal Cândido Rondon, membro do Grupo de Pesquisas e Estudos em Primeira Infância (GEPEPI), e-mail: vivib.dorecki@gmail.com
\end{abstract}

\section{RESUMO}

O objetivo deste artigo é explorar o impacto da pandemia da COVID-19 sobre a aprendizagem de crianças e adolescentes. A pandemia alterou toda a dinâmica social, impondo medidas sanitárias para barrar a disseminação do corona vírus. Com a obrigatoriedade do isolamento social todos os segmentos com aglomeração de pessoas foram atingidos. O maior impacto sofrido foi no ambiente escolar, onde milhares de crianças e adolescentes precisaram se adaptar a um novo modelo de aprendizagem, com aulas remotas em casa. Esse formato de ensino formal adotado na pandemia revelou vantagens e desvantagens exploradas no texto. Para a realização deste trabalho utilizou-se principalmente a pesquisa dedutiva, com investigação da literatura e legislação a respeito.

Palavras-chave: Pandemia. Isolamento. Escola. Aprendizagem.

\section{ABSTRACT}

The purpose of this article is to explore the impact of the COVID-19 pandemic on the learning of children and adolescents. The pandemic changed the entire social dynamic, imposing sanitary measures to stop the dissemination of the corona virus. With the mandatory social isolation, all segments with agglomeration of people were affected. The biggest impact suffered was in the school environment, where thousands of children and teenagers had to adapt to a new learning model, with remote classes at home. This formal teaching format adopted in the pandemic revealed advantages and disadvantages explored in the text. In order to carry out this work, deductive research was used mainly, with exploration of the literature and legislation on the subject.

Keywords: Pandemic. Isolation. School. Learning. 


\section{INTRODUÇÃO}

Esse artigo se propõe a definir e localizar geográfica e historicamente a pandemia da COVID-19, o que será feito no primeiro capítulo.

$\mathrm{Na}$ sequência, e considerando os efeitos da pandemia sobre as atividades cotidianas de todas as pessoas, buscará explorar os principais modelos de educação que inaugurou, o que será feito no segundo capítulo.

Igualmente, pretende investigar as principais repercussões da pandemia no desenvolvimento de crianças e adolescentes, propondo algumas reflexões, o que será feito no último capítulo.

A metodologia utilizada nessa pesquisa será a dedutiva, explorando, principalmente, a literatura a respeito do assunto (p.e. livros, artigos científicos, dados do Ministério da Educação), para chegar-se a conclusões possíveis.

\section{CONSIDERAÇÕES INICIAIS SOBRE O PERÍODO DA PANDEMIA}

Em março de 2020 os estudantes deixaram de frequentar as atividades presenciais nas escolas em razão do surgimento e alastramento da COVID-19 no Brasil, doença causada pelo corona vírus (SARS-CoV).

O primeiro caso conhecido da COVID-19 foi detectado na cidade Wuhan na China, em dezembro de 2019 e foi se espalhando para o mundo, deixando os populares com medo. A alta capacidade de disseminação fez com que a Organização Mundial de Saúde (OMS) declarasse, em 11 de março de 2020, emergência de saúde pública de nível internacional.

A COVID-19 não foi a primeira pandemia de que se tem notícia. Uma década antes, manifestou-se a gripe H1N1 que implicou em muito medo por parte da população e alterou a rotina de muitos estudantes que deixaram de realizar as suas atividades naquela ocasião. Foi necessário o desenvolvimento de vacinas para evitar a infecção e o agravamento da doença com a possibilidade de óbito. Contudo, a COVID-19 impactou surpreendentemente toda a população e isso mundialmente.

Inicialmente, não havia como conter a doença e o que se via era a contaminação em massa das pessoas, além de milhares de mortes e sequelas graves aos sobreviventes. Diante desse cenário, 
e no primeiro momento, foram determinadas (em âmbito interno, pela Lei n. 13.997/2020) ${ }^{6}$ medidas drásticas a serem adotadas visando conter a disseminação do vírus, como o isolamento social, a quarentena e a utilização de protocolos de segurança (p.e. utilização de máscaras, álcool em gel etc.).

Em relação ao emprego formal, consolidou-se o trabalho remoto (home office) e a adaptação dos sistemas de compra, venda e entrega de produtos (e-commerce, delivery, takeaway).

No tocante às atividades escolares e acadêmicas, considerando a impossibilidade de aglomeração e visando a alteração do cenário de contaminação, surgiram ou pelo menos se aprofundaram as aulas online.

Irrompe assim, nesse período de pandemia, um conflito entre o direito à educação e o direito à vida e, em última instância, o próprio direito à liberdade, todos esses valores consagrados no texto constitucional. Significa dizer que, entre preservar-se a vida por meio das medidas de prevenção e contenção da COVID-19 (dentre as quais o isolamento e a quarentena que requerem o distanciamento físico dos indivíduos), e a continuidade das atividades escolares especialmente dirigidas às crianças e aos adolescentes, priorizam-se a manutenção da saúde e a preservação da vida destes, colocando-se em segundo plano o direito de frequentar a escola (GUIZZO, MARCELLO, MULLER, 2020, p. 3).

A propósito disto, o próprio Estatuto da Criança e do Adolescente (Lei n. 8.069/1990) destina capítulo próprio relativo aos direitos e garantias asseguradas às pessoas em especial processo de desenvolvimento, privilegiando o direito à vida. Dessa forma, nas palavras de GUIZZO, MARCELLO e MULLER, para garantir tais direitos, há um movimento de deslocamento da educação "na escola" para as formas em que a "escola pode estar presente" (2020, p. 4), conforme será melhor analisado a seguir.

\subsection{A PANDEMIA E OS REFLEXOS IMEDIATOS NA EDUCAÇÃO ESCOLAR}

Sem dúvida a pandemia mundial do corona vírus fez com que tudo mudasse rápida e drasticamente. Um processo difícil e doloroso porque era imprescindível e irreversível a necessidade de alteração da rotina e aprender a lidar com o "novo" e adaptar-se em termos de

\footnotetext{
6 Além da Lei federal mencionada, importantes instrumentos normativos foram a Portaria n. 356/2020-MS e a Portaria Interministerial n. 05/2020 que estabeleceram determinadas ações, registrando a obrigatoriedade da observância das normas sob pena de responsabilidade. 0000-0002-6546-8611.
}

Ciências Sociais Aplicadas em Revista, v. 20, n. 38, p. 94-107, semestral, janeiro-junho, 2020. 
recursos tecnológicos, compreendidos em sentido técnico como sociocultural, conforme ensina HEINSFELD:

Um dos principais elementos na interpretação da tecnologia como artefato sociocultural diz respeito à ideia de que a evolução e o desenvolvimento dos artefatos não refletem somente uma evolução técnico-econômica, mas também as relações entre os sistemas e os ambientes em que se inserem. Nesse sentido, as alterações de artefatos se tratariam do fruto de aprimoramentos tanto das relações entre indivíduos, grupos, macrossistemas e o ambiente em que se inserem, junto a seus focos de interesse (2019, p. 5).

No campo educacional, em razão do ensino formal ter se dado, na absoluta maioria, de forma remota, tanto na rede pública quanto na rede privada, os impactos foram mais severos do que aqueles produzidos em outras áreas do cotidiano.

Conforme o levantamento realizado pelo Instituto Nacional de Estudos e Pesquisas Educacionais Anísio Teixeira (INEP), a média no país foi de 279 dias de suspenção de atividade presenciais durante o ano letivo de 2020, considerando as escolas públicas e privadas:

\footnotetext{
O levantamento mostra que $99,3 \%$ das escolas brasileiras suspenderam as atividades presenciais. Em função disso, parte delas também ajustou a data do término do ano letivo de 2020, visando ao enfrentamento das questões pedagógicas decorrentes dessa suspensão. As escolas públicas sentiram uma necessidade maior de fazer a adequação. Pouco mais de $53 \%$ delas mantiveram o calendário. Por outro lado, cerca de $70 \%$ das escolas privadas seguiram o cronograma previsto.

$\mathrm{O}$ percentual de escolas brasileiras que não retornaram às atividades presenciais no ano letivo de 2020 foi de $90,1 \%$, sendo que, na rede federal, esse percentual foi de $98,4 \%$, seguido pelas escolas municipais $(97,5 \%)$, estaduais $(85,9 \%)$ e privadas $(70,9 \%)$. Diante desse contexto, mais de $98 \%$ das escolas do País adotaram estratégias não presenciais de ensino (INEP, online, 2021).
}

Assim, os alunos tiveram dificuldades para acompanhar as aulas remotas, não apenas pelo desafio próprio em se manter atrás das telas e absoluto afastamento do ambiente escolar. Dificuldades em ter acesso a equipamentos ou à internet foram por vezes instransponíveis. Isso certamente trouxe, entre outras consequências, um déficit conteudístico para o alunado.

No que concerne aos alunos do ensino médio, especialmente os que estavam no último ano, tiveram maiores problemas em relação os vestibulares e às provas do Exame Nacional do Ensino Médio (ENEM).

Mas foram as crianças das séries iniciais que mais foram afetadas pela pandemia do corona vírus no campo educacional. Além do início e do desenvolvimento da alfabetização, era necessário contar com a ajuda imprescindível dos familiares ou responsáveis para acompanhar suas atividades. 
Sabe-se que muitos familiares, erradamente, não participam do processo ensinoaprendizagem ou porque acreditam seriamente que o ensino e a educação são obrigações apenas da escola, ou porque trabalham e não cessaram suas atividades mesmo em tempo de isolamento ou distanciamento social; ou porque não possuem o mínimo de condições para auxiliarem os filhos ou, ainda, simplesmente porque não há quem possa responder por essas crianças. Diga-se, de passagem, que muitas crianças que não eram, se tornaram órfãos no período da pandemia, justamente em razão da Covid-19.

As autoras GUIZZO, MARCELLO e MULLER sintetizam esse período de forma muito elucidativa. Para elas essa alteração radical atingiu todos os atores do processo ensinoaprendizagem:

\begin{abstract}
Crianças (na sua condição de aluno/as), responsáveis e professoras foram surpreendidos e precisaram rever suas práticas de formas sensivelmente diferentes daquelas com que estavam habituados e familiarizados. Professoras precisaram aprender a preparar materiais didáticos (atividades, videoaulas, recados motivacionais etc.), mas também a lidar com aplicativos e/ou ambientes virtuais nos quais disponibilizar esses materiais. Suas rotinas alteraram-se bruscamente, pois, além de planejar, também precisaram aprender a gravar, estar online e sanar dúvidas. Crianças, por sua vez, precisaram aprender não só com suas professoras, cujas aulas virtuais foram disponibilizadas inclusive em plataformas como youtube, mas também com seus próprios responsáveis, num espaço completamente familiar (suas casas), ainda que num tempo flexível, negociável. Pode-se dizer que essas novas noções de espaço e tempo estão imbricadas com a produção de novos modos de pensar a educação e os processos pedagógicos. Os responsáveis precisaram mediar a relação entre professoras e crianças, reaprender conteúdos até então esquecidos e aprender a lidar com aplicativos e ambientes virtuais: baixar conteúdos, acessar sites de bibliotecas, filmar atividades, tirar fotografias, fazer postagens que comprovassem a realização das atividades. Para todas essas tarefas, precisaram investir grande parte do seu tempo em uma nova demanda agora a eles imposta, bem como assumir o uso efetivo das tecnologias digitais, já que essas compõem as condições de possibilidade para a continuidade da educação nesse momento vivido. (2020, p. 7)
\end{abstract}

Essa alteração do cotidiano e das rotinas educacionais fez com que surgissem novos "modelos" de educação, próprios do período da pandemia, de acordo com a reflexão a seguir delineada.

\title{
3 MODELO DA EDUCAÇÃO NO PERÍODO DA PANDEMIA
}

Segundo Guizzo, Marcello e Muller, no campo educacional, a palavra de ordem desse período de pandemia foi, sem dúvida, a flexibilização, sugerindo lidar com "outras linguagens, outras temporalidades e, consequentemente, com diferentes experiências” (2020, p. 7).

Ciências Sociais Aplicadas em Revista, v. 20, n. 38, p. 94-107, semestral, janeiro-junho, 2020. 
E conforme mencionado acima, com a necessária implantação de estratégias para o controle da doença, dentre as quais, o fechamento das escolas, houve, igualmente o surgimento de muitos desafios na área da educação e a busca por novas ferramentas e metodologias para o ensino de crianças e adolescentes.

O primeiro desafio foi pensar uma forma de educação em que a transmissão do conhecimento não fosse interrompida e que chegasse aos alunos.

Considerando os avanços no campo da tecnologia, mais especificamente dos equipamentos eletrônicos (p.e. computadores, tablets, telefones celulares), da internet e das formas de comunicação (e-mail, whatsapp, páginas de relacionamento), foram desenvolvidas as plataformas, aplicativos, programas e estruturas de transmissão de aulas e de materiais de forma remota. Tudo isso, embora já utilizado por meio dos diversos cursos à distância implementados no país (famosos cursos EAD), sem dúvida foi aperfeiçoado nesse período de pandemia.

Diante disso, surgiram e foram acentuados alguns formatos de educação para o período de pandemia sendo possível o modelo de ensino em casa (o já conhecido homeschooling adotado por algumas famílias foi transformado em regra $)^{7}$ e, posteriormente, o modelo híbrido, alternando a ida dos alunos à escola e em casa com o revezamento destes (em uma semana um aluno ia para escola e o outro ficava em casa realizando as atividades enviadas pelos professores).

No caso do ensino em casa, principalmente para as séries do ensino fundamental, foram desenvolvidas atividades que eram enviadas para os alunos por meio dos seus familiares, que deveriam retirá-las na unidade escolar ou que eram enviadas por via remota. A fim de acompanhar as crianças de forma diferenciada nas séries iniciais, essas atividades deveriam ser devolvidas e corrigidas pelo docente responsável.

Nos termos do mencionado supra, o ensino em casa e mesmo o híbrido (quando em casa), depende de acesso dessas famílias a equipamentos (celulares, tablets, notebooks ou computadores de mesa) e internet, o que para muitas famílias era absolutamente impossível. Demais disso, o "letramento" digital era, sem dúvida, outro obstáculo das famílias nesse período ${ }^{8}$. Não obstante as

\footnotetext{
${ }^{7} \mathrm{O}$ ensino remoto, típico desse período de pandemia, não pode ser utilizado como sinônimo do homeschooling, muito embora, sejam modelos de ensino realizado em casa. Trata-se do ensino realizado pelos pais no âmbito doméstico e que já possui uma adesão bastante significativa no país. Informações disponíveis em: Homeschooling: Conheça o método de ensino que cresce no Brasil | Educa Mais Brasil.

${ }^{8}$ Nesse sentido, de acordo com o levantamento da imprensa (startup Descomplica), após a oitiva de pelo 800 pais e responsáveis de estudantes dos ensinos fundamentais e médios no período, do total, demonstra que $80 \%$ das famílias relataram problemas de infraestrutura (problemas ou falta de internet/equipamentos e dificuldades com plataformas). Outros $54 \%$ esbarraram em barreiras socioemocionais e $16 \%$ enfrentaram questões de letramento digital. Muitos países não têm acesso a internet conforme diz a reportagem $(\mathrm{CNN}$, online $)$.
} 
dificuldades mencionadas, "as telas" eram o único canal possível para continuidade do ano letivo, conforme destaca ALVES:

\begin{abstract}
Escola na tela: gigantesca desigualdade educacional existe em função da disparidade de acesso tecnológico, o conhecimento produzido na escola vai muito além de conteúdo, ele é permeado por valores éticos, morais político e social. A escola na tela tornou-se o único canal possível para a continuidade do no letivo. Surgiram inúmeras dificuldades como a dificuldades de acesso à internet e a aparelho de celular ou até mesmo computador (ALVES, online).
\end{abstract}

De outro lado, muitos familiares buscavam as atividades destinadas aos filhos. Porém, dentro desse universo, houve casos de pais que sequer buscavam as atividades, não conseguiam acompanhar os filhos, não devolviam ou quando devolviam, estas estavam em branco. Esse cenário revelou uma outra verdade: a de que falta de comprometimento da família no processo ensinoaprendizagem ou da ausência de conhecimento a respeito da fundamentabilidade da participação do núcleo familiar nesse processo.

Apenas no intuito de refletir a respeito do sucesso do homeschooling destacado por seus defensores, e cuja realidade em alguma medida se assemelha ao ensino em casa do atual período de pandemia, é preciso chamar a atenção de que esse formato não é gratuito, muito pelo contrário, porque demanda investimento em material e tecnologia, sem contar a dedicação de algum familiar na qualificação dos filhos, abdicando, muitas vezes de sua profissão, para acompanhar esse processo (GUIZZO, MARCELO, MULLER, 2020, p. 6-7). Embora o homeschooling seja uma prática excepcional em nosso país, a realidade da maioria das famílias brasileiras é completamente distinta, em que a "ausência" é a regra (p.e. de um dos pais ou de ambos no núcleo familiar no processo ensino-aprendizagem, de condições financeiras para investimento em tecnologia, de compreensão da necessidade de sua participação no processo).

Sem dúvida nenhuma, esse período demandou um esforço gigantesco das pessoas envolvidas no processo ensino-aprendizagem. Os professores tiveram que se adaptar inclusive em termos de aquisição de equipamentos e de conhecimento na área da informação. Familiares e responsáveis pelos alunos tiveram que, igualmente, buscar meios para garantir aos filhos a educação via remota, além de participarem ativamente do processo ensino-aprendizagem. Alunos tiveram que se familiarizar com o ensino remoto e, fazer um esforço grandioso para manter a atenção e a disciplina para conseguirem alcançar o objetivo que poderia ser a alfabetização, o aperfeiçoamento, ou o preparo para vestibular entre outras formas de concurso ou de qualificação para o futuro mercado de trabalho.

Ciências Sociais Aplicadas em Revista, v. 20, n. 38, p. 94-107, semestral, janeiro-junho, 2020. 
Em que pese o esforço de todas as partes, o ensino remoto também desnudou muitas mazelas, como a mencionadas acima. Além da ausência da falta de participação dos familiares, por diversas razões, no processo ensino-aprendizagem, o despreparo em termos de conhecimento dos profissionais da educação e da carência de estrutura nas unidades escolares de toda a federação (principalmente das escolas públicas) para o desenvolvimento do ensino remoto também foi evidenciado.

Quanto a esse aspecto, importa destacar que o direito à educação em sentido formal acima referenciado contempla "a qualidade social que se oferta nas escolas" (SANTOS, 2019, p. 3). Nesse sentido, não só os profissionais da educação devem preparar-se em termos de conhecimento digital e aquisição de equipamentos apropriados para o desenvolvimento das aulas on line, como as escolas devem ter organização física para bem acomodar o alunado, como estrutura tecnológica para contemplar o ciberespaço (MODELSKI, GIRAFFA, CASARTELLI, 2019), cuja demanda se "aprofundou" no período de pandemia, antecipando uma era que ainda estava por ser instalada no campo educacional. É dizer que, além da necessidade de a escola se adaptar para a oferta do ensino remoto necessariamente deve "[...] propiciar o desenvolvimento das habilidades imperativas para a cidadania no século XXI e a indispensabilidade de serem exploradas as potencialidades das redes digitais.” (HEINSFELD, 2019, p. 2)

Em sentido oposto, foi possível, embora em menor número, enxergar alguns benefícios do ensino em casa, como a aproximação de familiares das crianças e adolescentes, o aprofundamento dos vínculos e a descoberta da importância do papel destes no desenvolvimento dos filhos e na aquisição de conhecimento.

Há que se destacar ainda a flexibilização e personalização de horários, e com isso, ritmos de aprendizagem ditados pelos estudantes. Igualmente, menor pressão social, menos possibilidade de exposição ao bullying e do assédio e, portanto, menos casos relacionados a ansiedade por essas causas.

Em relação aos docentes, estes tiveram que sair da sua zona de conforto e descobrir novas formas de ensinar. Para os professores houve o controle da turma podendo tirar dúvidas individualmente e realizar atividades mais diversificadas e interativas.

Fato é que a pandemia aprofundou uma realidade que já estava instalada do ensino remoto e de que muitas das alterações produzidas viriam para ficar. 


\section{CONSEQUÊNCIAS DA PANDEMIA NO DESENVOLVIMENTO EDUCACIONAL}

Não obstante essas considerações a respeito de possíveis "vantagens" e "desvantagens" do ensino remoto, uma questão que veio à tona, nesse momento, foi a respeito do papel do professor e da escola na formação do indivíduo.

Quanto ao papel da escola na vida de um indivíduo, muitas questões podem ser lembradas.

Em primeiro lugar, o ambiente escolar é fundamental para o desenvolvimento das habilidades socioemocionais. Na escola o aluno aprende a se relacionar com outras crianças. Dentro de sala de aula a criança trabalha em equipe, coloca as suas ideias e aprende a escutar os demais, suas experiências e próprias percepções de mundo. Nesse sentido, explica Alves que a:

Escola é ferramenta de cultura e sua função social é ampla e complexa, o conhecimento produzido na escola vai muito além de conteúdo, ele é permeado por valores éticos, morais, políticos e sociais. O ambiente escolar é fundamental para o desenvolvimento das habilidades socioemocionais. Dentro da escola o aluno aprende a se relacionar, a respeitar as diferenças, a trabalhar em equipe, a expor ideias e a ouvir opiniões, além de tolerar frustrações e adiar recompensas (INSTITUTO ROGE, online).

Em sentido idêntico, ou seja, da importância da escola enquanto espaço de construção do saber formal, assevera Santos:

[...] mesmo que a educação seja uma prática social corrente em diversos espaços e tempos e de diferentes modos, é possível afirmar que, sem o estabelecimento escolar, o direito a ela seria mais difícil de ser garantido, e ao se investir em qualidade da educação que se oferece nesses lugares, considera-se que deve compreender acesso, permanência, sucesso, organização e participação nas discussão do processo político e pedagógico, pois educação é produção de saber e o saber é, reconhecidamente, expressão de relações políticas e ideológicas $(2019$, p. 4-5)

Ainda segundo a autora, a escola enquanto instituição, constitui-se num ambiente de formação da cidadania e como "[...] espaço privilegiado de proteção de direitos das crianças e dos adolescentes, que em articulação com outras instituições estrutura o Sistema de Garantia de Direitos e fortalece a rede social protetiva de direitos" (SANTOS, 2019, p. 8-9)

Infelizmente com a pandemia, com o fechamento das creches e das escolas, as crianças perderam essa interação e as vantagens que ela traz.

É possível, igualmente, verificar que o período de isolamento gerou um enorme estresse em todas as pessoas, afetando imensamente a suade mental, aumentando os sintomas de depressão 
e ansiedade. Mas em relação as crianças e aos adolescentes ${ }^{9}$, esses danos podem ser ainda maiores, por serem considerados indivíduos em desenvolvimento.

Estima-se, em revisão recente de 29 pesquisas, que os sintomas de ansiedade e depressão entre crianças e adolescentes dobraram após o início da pandemia do coronavírus. O trabalho, reuniu dados de 80879 jovens com 18 anos ou menos de diversos países. Antes da pandemia, levantamentos sugeriam que sintomas depressivos eram comuns a 12,9\% desse grupo. Já durante a crise do coronavírus, essa taxa subiu para $25,2 \%$. Os sinais ansiosos por sua vez, aumentaram de $11,6 \%$ para 20,5\%. E o índice tendia a ser maior conforme o avanço da pandemia. Na revisão, os pesquisadores sugerem que a falta de convívio social, o aumento do estresse na família e a limitação de certas atividades estão entre as hipóteses para a piora no bem-estar mental (VEJA SAÚDE, online).

Outrossim, com a permanência tanto das crianças quanto dos adultos que não puderem realizar as suas atividades habituais de trabalho e estudo, houve o aumento da violência, gerado justamente a partir do estresse da pandemia. Nesse sentido, tendo em vista o isolamento social muitas crianças e adolescentes foram vítimas de violência doméstica e até mesmo sexual. Quanto a isso, explicitam-se razões que vão da "impaciência do mundo adulto, do agravamento de violências já existentes e o aumento da exposição ao mundo virtual” (JORNAL DA USP, online).

O mais grave desse cenário de violência, foi a diminuição de denúncias e de procedimentos relacionados a esse tipo de violência, justamente em razão da consequente diminuição da procura pelo atendimento ao serviço de proteção. Quanto a isso, o papel da escola e dos profissionais da educação sempre foi extremamente relevante já que, através deles, muitos casos de violência são reportados ou diretamente constatados nos corpos das vítimas de maus tratos (JORNAL DA USP, online).

Portanto, o afastamento do convívio com amigos e com toda a rede de apoio, agravou as vulnerabilidades das crianças e adolescentes nesse período de pandemia.

Mas não foi só a saúde mental que foi afetada nesse período. Problemas de saúde surgiram ou foram agravados justamente em razão do isolamento social. Nesse sentido, constatou-se o aumento do sedentarismo e da obesidade e exagero no uso de telas, como televisão, computadores, tablets e smartphones. De acordo com os dados da OMS:

\footnotetext{
${ }^{9}$ Em relação aos adolescentes, há, por parte da literatura, destaque quanto a esses efeitos: Em adolescentes, depressão e ansiedade formam um conjunto de sentimentos ainda mais complexo - é nessa fase que se constrói uma identidade e a convivência com os pares. Mau humor, alterações de sono, agressão verbal e desinteresse por atividades cotidianas podem sugerir problemas. Principalmente se prolongados, merecem atenção dos responsáveis (VEJA SAÚDE, online).
} 
Os jovens ganharam mais peso ao longo da pandemia do que antes dela. Os percentuais de crianças com obesidade ou sobrepeso de 12 a 15 anos passou de $38,7 \%$ para $43,4 \%$, do grupo avaliado, desde o início da circulação do coronavírus até janeiro deste ano. Entre os que tinham 16 a 17 anos, passou de $36,5 \%$ para $38,2 \%$.

E no Brasil, segundo IBGE, Instituto Brasileiro de Geografia e Estatística, uma em cada três crianças entre cinco e nove anos está acima do peso (INSTITUTO CADES, online).

Justamente a tecnologia, que veio para auxiliar os estudantes e os profissionais nesse período de pandemia (por meio das ferramentas mencionadas), acabou também gerando outros efeitos como aumentando a distração destes com jogos e redes sociais, o que fez com que muitos alunos perdessem o ritmo de aula e, em consequência, tivessem prejuízos na própria aprendizagem. Não se pode esquecer, ainda, de que a utilização das plataformas digitais aumentou ainda mais a exposição das crianças e adolescentes a outras formas de violência, como o ciberbullyng, pornografia infantil e assédio.

E em relação à saúde coletiva, com a redução da circulação dos meios de transporte para serviços não essenciais, a redução no acesso aos serviços tanto da atenção primária quanto a atenção especializada, incluindo a redução de cirurgias eletivas e até mesmo tratamentos oncológicos e de cuidados de emergência e saúde, aliados ao medo da COVID-19, os problemas de saúde já existentes foram agravados. Segundo a Agência Brasil de Notícias:

\footnotetext{
A pandemia de covid-19 pode ter feito com que mais de 1 milhão de cirurgias eletivas e emergenciais tenham deixado de ser feitas no Brasil em 2020. O levantamento usou dados do Data SUS, do Ministério da Saúde, sobre o número de cirurgias feitas no país no período de 2016 a 2020. Por meio de um modelo estatístico, a pesquisa estimou o volume cirúrgico esperado para o período de pandemia, entre março e dezembro do ano passado. Ao comparar o número esperado com os dados reais fornecidos pelos estados, verificou-se um acúmulo de mais de 1,1 milhão de cirurgias, a maioria delas (928.758) eletivas, aquelas que não são consideradas de urgência (AGÊNCIA BRASIL, online).
}

E embora esse não seja a atribuição da escola, sem dúvida, havia, por parte da escola, a supressão de várias necessidades das crianças e adolescentes. Desse modo, com o fechamento das escolas e das creches, além de perdas nas receitas familiares, houve também o aumento da fome e do risco alimentar.

Quanto ao papel do professor em sala de aula, esse é personalizado e de importância essencial. Além de estimular as diversas competências disciplinares, é responsável por transmitir conhecimento e modificar o meio; e dentro deste papel fundamental em nossa sociedade, é necessário que haja um olhar diferenciado para o aluno e suas necessidades, que possa haver um 
reconhecimento das habilidades e até das desabilidades, o que só pode ser feito, presencialmente, olho-no-olho (LIMA, p.14, 2012). Nesse reconhecimento, busca a superação e avanços, em seu papel como agente formador, para que sejam atingidos os objetivos pedagógicos (VASCONCELLOS, 2011).

Com seu olhar atento, o professor também é um agente fundamental para a revelação dos riscos a que são expostos seus alunos e atuar no sentido de cessar a violência ou o abuso.

Qualquer que seja a tecnologia e por mais avançada que seja, não tem o condão de substituir as competências do educador. Não se trata apenas de transmitir conhecimentos, mas de influir com seu comportamento, acolher com sua percepção, mudar perspectivas, a partir da sua visão de mundo.

\section{CONSIDERAÇÕES FINAIS}

Por meio desse artigo, se pretendeu refletir a respeito do processo ensino aprendizagem de crianças e adolescentes no período de pandemia da COVID-19. Além disso, objetivou-se reflexionar a respeito de possíveis vantagens ou prejuízos no desenvolvimento destes nesse período.

Esse período fez surgir vários desafios tanto para professores quanto para alunos. Tornou mais evidente as dificuldades e as diferenças entre os educadores, escola e alunos. A única ligação entre estes foi o uso da tecnologia. No entanto, não alterou o papel e a importância do professor e da escola na formação do indivíduo.

Verificou-se, essencialmente, que a escola é um dos principais ambientes de desenvolvimento cognitivo e, dessa forma, torna-se responsável por criar estratégias para que a aprendizagem se concretizasse. Da mesma sorte, que a escola tem sim um papel muito importante na educação do aluno como encontrar novos caminhos para o ensino de crianças e adolescentes, além de ser um canal para atendimento de demandas e necessidades especiais relacionadas às crianças e adolescentes.

Os professores, por sua vez, do mesmo modo possuem um papel fundamental enquanto agentes de formação de valores pessoais e de reconhecimento das especiais vulnerabilidades relacionadas as crianças e adolescentes.

A importância da escola enquanto instituição, reflete-se no referencial de apoio à rede de proteção e para assegurar os direitos mais fundamentais das crianças e dos adolescentes a ela vinculados.

Ciências Sociais Aplicadas em Revista, v. 20, n. 38, p. 94-107, semestral, janeiro-junho, 2020. 
A pandemia da COVID-19 não apenas alterou a rotina e criou novos modelos ou formas de ensinar na nesse período, mas também evidenciou a importância de todos esses personagens no processo ensino-aprendizagem.

Não obstante reconhecer-se a necessária alteração do cotidiano na vida de todas as pessoas, face ao período pandêmico, igualmente se reconhece que essa alteração impactou diferentemente as pessoas atingidas, notadamente crianças e adolescentes, por se encontram em desenvolvimento físico e psicológico, com especial destaque às que se encontram em condição de maior vulnerabilidade social.

\section{REFERÊNCIAS}

ALVES, Carmem Lúcia Ferreira. A nova realidade da educação durante o período de pandemia. Fundação Roge. Disponível em: https://www.fundacaoroge.org.br/blog/a-novarealidade-da-educacao-durante-o-periodo-de-pandemia. Acesso em: 13 out. 2021.

CNN Brasil. PESQUISA: Maioria dos estudantes teve problemas no acesso à internet durante aulas remotas. Disponível em: <Pesquisa: Maioria dos estudantes teve problemas no acesso à internet durante aulas remotas |CNN Brasil $>$. Acesso em: 13 out. 2021.

EDUCA mais Brasil. HOMESCHOOLING: Conheça o método de ensino que cresce no Brasil. Disponível em: Homeschooling: Conheça o método de ensino que cresce no Brasil | Educa Mais Brasil. Acesso em: 13 out. 2021.

GUIZZO, Bianca Salazar; MARCELLO, Fabiana de Amorim; MULLER, Fernanda. A reinvenção do cotidiano em tempos de pandemia. Revista Educação e pesquisa. Universidade de São Paulo, São Paulo, v. 46, 2020. Disponível em: < v. 46 (2020) | Educação e Pesquisa (usp.br)>. Acesso em 06 Dez. 2021.

HEINSFELD, Bruna Damiana. O discurso sobre tecnologias nas políticas públicas em educação. Revista Educação e pesquisa. Universidade de São Paulo, São Paulo, v. 45, 2019. Disponível em: < v. 45 (2019)| Educação e Pesquisa (usp.br)>. Acesso em 06 Dez. 2021.

INSTITUTO Cades. SEDENTARISMO aumenta entre as crianças durante o período de pandemia. Disponível em: <Sedentarismo aumenta entre as crianças durante a pandemia (institutocades.org.br)>. Acesso em: 13 out. 2021.

INEP - Instituto Nacional de Estudos e Pesquisas Educacionais Anísio Teixeira. Disponível em: https://www.gov.br/inep/pt-br/assuntos/noticias/censo-escolar/divulgados-dados-sobre-impactoda-pandemia-na-educacao. Acesso em: 13 out. 2021.

JORNAL USP. CASOS de violência contra crianças e adolescentes crescem na pandemia. 07/05/2021. Disponível em: Casos de violência contra crianças e adolescentes crescem na pandemia - Jornal da USP. Acesso em: 11 out. 2021. 
LIMA, Iris Giane Soares. A dislexia e o contexto escolar. Anhanguera Educacional, v. X, n. N, 2012.

MODELSKI, Daiane; GIRAFFA, Lúcia M.M.; CASARTELLI, Allam de Oliveira. Tecnologias digitais, formação docente e práticas pedagógicas. Revista Educação e pesquisa. Universidade de São Paulo, São Paulo, v. 45, 2019. Disponível em: < v. 45 (2019) |Educação e Pesquisa (usp.br)>. Acesso em 06 Dez. 2021.

Organização Pan-Americana de Saúde (OPAS). Organização Mundial da Saúde (OMS). HISTÓRICO da pandemia do COVID-19. Disponível em: Histórico da pandemia de COVID19 - OPAS/OMS | Organização Pan-Americana da Saúde (paho.org). Acesso em: 13 out. 2021.

PANDEMIA impede a realização de mais de um milhão de cirurgias em um ano. 29/09/2021. Disponível em: <https://agenciabrasil.ebc.com.br/saude/noticia/2021-09/pandemia-impederealizacao-de-mais-de-1-milhao-de-cirurgias-em-um-ano:. Acesso em: 12 nov. 2021.

RAMOS, Daniel Gómez. La acogida de la vunerabilidad de la infância: la responsabilidad éticapedagógica en la escuela. Revista Educação e pesquisa. Universidade de São Paulo, São Paulo, v. 46, 2020. Disponível em: < v. 46 (2020)| Educação e Pesquisa (usp.br)>. Acesso em 06 Dez. 2021.

SANTOS, Émina. A educação como direito social e a escola como espaço protetivo de direitos: uma análise à luz da legislação educacional brasileira. Revista Educação e pesquisa. Universidade de São Paulo, São Paulo, v. 45, 2019. Disponível em: < v. 45 (2019)| Educação e Pesquisa (usp.br)>. Acesso em 06 Dez. 2021.

SANTOS, Willian Lima; FERRETE, Anne Alilma Slva Souza; ALVES, Manoel Messias Santos. Cenários virtuais de aprendizagem como recurso pedagógico diante da pandemia do novo coronavírus: relatos das experiências docentes. Educação. V. 46, Jan./Dez. 2021. Disponível em: < Educação, v. 46, 2021 - Jan./Dez. - Publicação contínua (ufsm.br)>. Acesso em 06 Dez. 2021.

VEJA Saúde. SINAIS de depressão e ansiedade dobraram em jovens na pandemia, diz estudo. Disponível em: < Sinais de depressão e ansiedade dobraram em jovens na pandemia, diz estudo | Veja Saúde (abril.com.br)>. Acesso em: 13 out. 2021.

VASCONCELLOS, C. S. Formação didática do educador contemporâneo: desafios e perspectivas. In: UNIVERSIDADE ESTADUAL PAULISTA. Prograd. Caderno de Formação: formação de professores didática geral. São Paulo: Cultura Acadêmica, 2011, p. 33-58, v. 9. 